\title{
Haldane's rule and American black duck $\times$ mallard hybridization
}

\author{
Ronald E. Kirby, Glen A. Sargeant, and Dave Shutler
}

\begin{abstract}
Species ratios and rangewide distributions of American black ducks (Anas rubripes Brewster, 1902) and mallards (Anas platyrhynchos L., 1758) have undergone recent changes. Mechanisms behind these changes are not known with certainty, but recent investigations have focused on the possibility of competitive exclusion and the consequences of hybridization. Consequences of hybridization have been difficult to assess because of the difficulty in identifying hybrids beyond the $F_{1}$ generation and lack of means to quantify introgression in wild populations. We documented a postmating isolating mechanism between the two species that follows Haldane's rule in controlled, interspecific matings in captive populations. Hybridization reduces the proportion of $F_{1}$ females available to return to the breeding grounds in the subsequent year. This effect, although likely small in overall population consequences in any year, may be of local significance and may contribute to recent reports of range shifts in both American black ducks and mallards.
\end{abstract}

Résumé : L'importance relative des canards noirs (Anas rubripes Brewster, 1902) et des canards colverts (Anas platyrhynchos L., 1758) et leur répartitiol'échelle de leur aire totale ont encouru des modifications récentes. Les mécanismes responsables de ces changements ne sont pas connus avec précision, mais des études récentes ont examiné l'exclusion par compétition et les conséquences de l'hybridation. Les conséquences de l'hybridation sont difficiles à évaluer car il n'est pas facile d'identifier les hybrides au-delà de la génération $F_{1}$ et il n'y a pas de moyen pour quantifier l'introgression chez les populations sauvages. Nous avons étudié un mécanisme d'isolement entre les deux espèces après l'accouplement lors d'accouplements interspécifiques contrôlés chez des populations en captivité. L'hybridation réduit le pourcentage de femelles de $\mathrm{F}_{1}$ disponibles pour retourner sur les aires de reproduction l'année suivante. Cet effet, bien que limité en conséquences sur l'ensemble de la population pour une année donnée, peut être d'importance locale et peut contribuer aux changements dans les aires de répartition signalés tant chez les canards noirs que chez les canards colverts.

[Traduit par la Rédaction]

\section{Introduction}

Several reviews have addressed the decline of the American black duck (Anas rubripes Brewster, 1902; hereafter, black duck), both absolutely and relative to the mallard (Anas platyrynchos L., 1758) (Barske 1968; Rusch et al. 1989; Conroy and Krementz 1990; Nichols 1991; Nudds et al. 1996). Potential negative consequences of hybridization for the black duck have been a common theme. Discussion has led to extended debate (e.g., Ankney et al. 1987, 1989; Conroy et al. 1989); these authors viewed hybridization vari-

Received 15 April 2004. Accepted 24 November 2004.

Published on the NRC Research Press Web site at http://cjz.nrc.ca on 4 February 2005.

R.E. Kirby ${ }^{1,2}$ and G.A. Sargeant. Northern Prairie Wildlife Research Center, US Geological Survey, Jamestown, ND 58401, USA.

D. Shutler. Department of Biology, Acadia University, Wolfville, NS B4P 2R6, Canada.

${ }^{1}$ Corresponding author (e-mail: ronald_kirby@usgs.gov). ${ }^{2}$ Present address: US Geological Survey, Western Regional Office, 909 1st Avenue, 8th Floor, Seattle, WA 98104, USA. ously, from an extreme threat to the black duck to less important than competitive exclusion. Johnsgard (1963) considered the capacity of waterfowl to hybridize as evidence of an effective isolating mechanism that maintains the integrity of species, exactly the opposite conclusion from that drawn by many from observations of interactions between black ducks and mallards. Only Nudds et al. (1996) have distinguished between phenomena that might reduce black duck numbers and those that could cause the species to disappear. Experiments evaluating introgression have not been performed.

Primary sex ratios (at fertilization) of waterfowl are 1:1 (Johnson et al. 1992), which is also the case in other birds (Clutton-Brock 1986). Secondary sex ratios (at hatch) are likewise 1:1 (Blums and Mednis 1996). Hybrids between species, however, often show preferential sterility or inviability of the heterogametic (XY) sex, which in birds is the female. This phenomenon, called Haldane's rule, dates from 1922 when J.B.S. Haldane observed that

When in the offspring of two different animal races one sex is absent, rare, or sterile, that sex is the heterozygous [heterogametic or XY] sex. 
Recent surveys have suggested that this rule holds in all animals known to possess sex chromosomes (Orr 1997). Hybrid inviability in birds has long been known (e.g., Guyer 1909) and is widespread (Gray 1958), as is hybridization per se (Grant and Grant 1992). The cause of hybrid sterility and inviability is between-locus incompatibility, the mechanics of which are not of concern here (but for details see Orr 1997).

Given the ubiquity of Haldane's rule, and its known applicability to birds, the occurrence of this phenomenon in hybrids between black duck and mallard is predictable, but the question has not been investigated to date. In this paper, we report sex ratios of $F_{1}$ hybrids between black ducks and mallards, progeny of backcrosses to parental forms, and matings of $F_{1}$ inter se. We discuss the potential consequences of our findings to interpretations of species numbers and ratios of breeding waterfowl in the wild.

\section{Methods}

We analyzed results of mating trials between wild mallards and wild black ducks in propagation facilities. The original experiments were not designed to evaluate sex-ratio variation, thus obviating reporting bias of the sort identified by Palmer (2000) in other studies of sex ratios in birds. To the best of our knowledge, birds we included in this retrospective analysis constitute the only matings of these species wherein identities of parent birds were certain and initial sex ratios (the sex of all live-hatched young within clutches) were measured. Our analysis was of hybrid viability through measure of living (= viable) young at hatch. The data did not permit evaluation of other aspects of viability and fertility of hybrid offspring. Their subsequent survival was not consistently recorded in the original experiments or was truncated by experimental design. Infertility is a common $F_{1}$ postzygotic incompatibility in birds (Price and Bouvier 2002), but no useful quantitative data were recorded regarding subsequent fertility of the birds we assessed (i.e., numbers of eggs that failed to hatch or of causes of hatch failure). Birds reared in North Dakota were maintained under US Fish and Wildlife Service animal care protocols; birds reared in Canada were cared for under the principles and guidelines of the Canadian Council on Animal Care.

In the early 1970 s, F.B. Lee reared a flock of captive $P_{1}$ mallards from California and $\mathrm{P}_{1}$ black ducks from New Brunswick (some hand-reared in North Dakota) at Northern Prairie Wildlife Research Center near Jamestown, North Dakota. In 1974-1976, a captive breeding program was established to develop various hybrids from these parental forms. F.B. Lee recorded identities of adults used in each cross and the sex and number of offspring in each clutch. We sorted these records by type of cross (mallard male $\times$ black duck female, black duck male $\times$ mallard female, etc.) and by generation of hybridization $\left(\mathrm{P}_{1}, \mathrm{~F}_{1}, \mathrm{~F}_{2}, \mathrm{~F}_{1}\right.$ backcross to mallard, $\mathrm{F}_{1}$ backcross to black duck, etc.). Almost all of these birds were examined by R.E.K. as live specimens or frozen carcasses when this study began; representative specimens have been deposited in the National Museum of Natural History, Washington, D.C. (Kirby et al. 2000).

Shutler et al. (1996) reared $F_{1}$ black duck $\times$ mallard hybrids from mallards and black ducks from Ontario and mal- lards from Saskatchewan. Randomly chosen pairs of adults were isolated in outdoor pens and allowed to form pair bonds; duckling sexes were determined by cloacal palpation. We sorted the progeny (all $\mathrm{F}_{1}$ ) by clutch.

Phillips $(1914,1915,1921)$ reared hybrids between black ducks and mallards. Although we could not locate his original notes, his statements in the literature were unequivocal regarding sexes of offspring in some crosses. Those that included complete counts of young are included here. Some specimens from his work were available as study skins in the Museum of Comparative Zoology, Harvard University, Cambridge, Massachusetts.

Sex ratios can potentially vary among broods to a greater extent than predicted by the binomial distribution. To accommodate the possibility of such "extrabinomial" variation, we used a ratio estimator for cluster samples of variable size (Cochran 1977, p. 66) to estimate proportions of males in clutches recorded by F.B. Lee; D. Shutler, C.D. Ankney, and D.G. Dennis; and J.C. Phillips (Table 1). We included pooled broods when estimating means, but excluded pooled broods when estimating among-brood variances used to compute confidence limits. We did not know whether $F_{1}$ sex ratios would be influenced by the species of the female parent, so we compared sex ratios for $F_{1}$ progeny of female black ducks and female mallards before pooling data. Because Haldane's rule predicts a preponderance of males among $\mathrm{F}_{1}$ progeny, we computed $95 \%$ lower bounds (equivalent to one-tailed tests) for $\mathrm{F}_{1}$ hybrids. We computed $95 \%$ confidence limits for other groups because we had no reason to expect sex ratios to depart from unity.

\section{Results}

$\mathrm{F}_{1}$ hybrid duckling progeny were preponderantly male and we found no evidence of differences in sex ratios associated with sexes of parents. Offspring of male black ducks and female mallards were $66 \%$ male $(\mathrm{SE}=6.5 \%)$ and those of male mallards and female black ducks were $63 \%$ male $(\mathrm{SE}=$ $7.5 \%$ ). Collectively, hybrid $\mathrm{F}_{1}$ progeny were $65 \%$ male $(\mathrm{SE}=4.9 \%, 95 \%$ lower bound $=0.56)$. Sex ratios did not vary significantly from unity for groups other than $F_{1}$ hybrids. Progeny of $\mathrm{F}_{1} \times \mathrm{F}_{1}$ matings were $45 \%$ male $(\mathrm{SE}=$ $8.2 \%)$ and $\mathrm{F}_{1} \times \mathrm{P}_{1}$ progeny were $50 \%$ male $(\mathrm{SE}=6.5 \%)$. Collectively, non- $\mathrm{F}_{1}$ offspring were $48 \%$ male $(\mathrm{SE}=2.2 \%$, $95 \% \mathrm{CI}=44 \%-53 \%$ ).

\section{Discussion}

Our analysis was based on data collected for other reasons and thus lacked the experimental design and some of the controls one would wish. For example, selecting $\mathrm{P}_{1}$ birds from allopatric populations to obviate the genetic consequences of previous contact between the species might have resulted in bias if mallard and black duck populations are genetically structured. Anas spp. have been variously considered panmictic (Parker et al. 1981; Ankney et al. 1986) or not (Rhodes et al. 1995), but there is reason to believe that male dispersal is not entirely random and that some genetic differences are likely (Anderson et al. 1992). Similarly, the circumstances of the captive rearing programs had some effects. The small size of some hybrid clutches in Jamestown 
Table 1. Black duck (Anas rubripes) $\times$ mallard (Anas platyrhynchos) clutches for which sex was known for all hatched young.

\begin{tabular}{|c|c|c|c|}
\hline \multirow[b]{2}{*}{ Cross } & \multicolumn{2}{|c|}{$\begin{array}{l}\text { Number of clutches } \\
\text { of hatched young }\end{array}$} & \multirow[b]{2}{*}{ Source } \\
\hline & Males & Females & \\
\hline \multirow{5}{*}{$\begin{array}{l}\text { Male black duck } \times \\
\text { female mallard }\end{array}$} & 3 & 4 & Phillips $1915^{*}$ \\
\hline & 10 & 2 & This study \\
\hline & 11 & 6 & This study \\
\hline & 2 & 2 & This study \\
\hline & 5 & 2 & Shutler et al. 1996 \\
\hline \multirow{10}{*}{$\begin{array}{l}\text { Male mallard } \times \\
\text { female black duck }\end{array}$} & 3 & 0 & This study \\
\hline & 8 & 6 & This study \\
\hline & 2 & 2 & This study \\
\hline & 5 & 4 & This study \\
\hline & 5 & 0 & Shutler et al. 1996 \\
\hline & 0 & 1 & Shutler et al. 1996 \\
\hline & 1 & 0 & Shutler et al. 1996 \\
\hline & 1 & 0 & Shutler et al. 1996 \\
\hline & 3 & 5 & Shutler et al. 1996 \\
\hline & 3 & 0 & Shutler et al. 1996 \\
\hline \multirow[t]{12}{*}{$\mathrm{F}_{1}$ backcrossed to $\mathrm{P}_{1}$} & 10 & 8 & Phillips $1915^{\dagger}$ \\
\hline & 9 & 5 & Phillips $1915^{\dagger}$ \\
\hline & 4 & 3 & This study \\
\hline & 7 & 8 & This study \\
\hline & 4 & 3 & This study \\
\hline & 3 & 2 & This study \\
\hline & 1 & 1 & This study \\
\hline & 9 & 9 & This study \\
\hline & 3 & 4 & This study \\
\hline & 7 & 4 & This study \\
\hline & 1 & 3 & This study \\
\hline & 9 & 12 & This study \\
\hline \multirow[t]{7}{*}{$\mathrm{F}_{1} \times \mathrm{F}_{1}$} & 6 & 19 & Phillips $1915^{\ddagger}$ \\
\hline & 10 & 4 & Phillips $1915^{\S}$ \\
\hline & 7 & 4 & Phillips 1921 \\
\hline & 6 & 3 & This study \\
\hline & 3 & 8 & This study \\
\hline & 4 & 4 & This study \\
\hline & 8 & 11 & This study \\
\hline
\end{tabular}

Note: "This study" refers to data collected by F.B. Lee in Jamestown, North Dakota.

* May have been from mixed broods.

${ }^{\dagger}$ Broods from two females that were combined.

*Phillips confined three males and four females together in a single pen. This value is the sum of the clutches.

${ }^{\S}$ Same parents as depicted in the previous line but from another year.

may be explained by the fact that this effort was part of a much larger captive rearing program in which disturbance by animal caretakers and by predators trying to gain entrance to the pens was a constant concern. This may have resulted in partial destruction of some clutches that could not be unequivocally documented by review of decade-old records. In both the Jamestown and Canadian studies, egg inviability was reported in incubator records and was an ultimate factor that also reduced numbers of hatched birds. Contrarily, we also cannot explain a few of the large clutches in both the Jamestown pens and in Phillips' (1915, 1921) studies (mean black duck clutch sizes vary from slightly more than 9 to 10 eggs, and decreases with season and whether the nest attempt is a re-nest or first attempt; Longcore et al. 2000). However, in Jamestown, eggs were sometimes removed to incubators if nests appeared abandoned and sometimes birds returned to laying thereafter. Continuous laying in these non-nutrient-limited birds was possible as has been observed in the wild (Arnold et al. 2002). We have no reason to believe that any of these circumstances would affect the sex ratio of eggs laid, but captive circumstances differ in many ways from circumstances in the wild. Similarly, we derived no insight in this study as to when differences in sex ratio occurred because reasons for inviability were not assessed. However, our postulate was that Haldane's rule, as a general explanation for the sex ratio observed, applied.

Notwithstanding the above caveats, $F_{1}$ young from black duck $\times$ mallard matings were preponderantly male as predicted by Haldane's rule; sex ratios of young in the other crosses were approximately $1: 1$. Considering the ubiquity of Haldane's rule, which applies even among domestic races of the mallard (Phillips 1914), this outcome was expected. Analyses have shown that this result is a nearly obligatory first step in the evolution of postzygotic isolation (Coyne and Orr 1989, 1997). Therefore, one would expect Haldane's rule to be expressed in matings between black ducks and mallards, which historically have been viewed as probably separated since the early Quaternary (Palmer 1976, p. 288; Avise et al. 1990; R.S. Palmer, personal communication). More recent analyses (McCracken et al. 2001) have suggested a much earlier origin of black ducks from a "monochromatic mallard-like ancestor that established itself in the New World well in advance of nominate mallards." This earlier origin (as opposed to peripatric speciation) lends greater weight to the expectation that Haldane's rule would apply in this circumstance. We cannot envision a simple means to expand this analysis to a reasonable field experiment because any such exercise would fail on the matter of determining the paternity of young.

The effects of hybridization on sex ratios of generations subsequent to the $F_{1}$ in waterfowl have not been investigated. We assumed that there were none for our analysis and found none in the few crosses for which we had data, but this was a very limited analysis from experiments not designed to address sex ratios per se. Price and Bouvier (2002) found that fertility of the homogametic sex in birds (male) was lost in the $F_{1}$ before viability of the heterogametic sex (female). This finding requires further study in black duck $\times$ mallard hybridization.

Given the imperfection of premating isolation in this species pair, there is a role for postmating isolation in maintaining species integrity even when $F_{1}$ fitness loss is modest (Price and Bouvier 2002). This phenomenon cannot be discerned within wild populations when species relations are assessed by relative counts of parental species and putative hybrids, and only $\mathrm{F}_{1}$ hybrids can be consistently and accurately identified (Kirby et al. 2000). But there are population phenomena of interest that may be a consequence of this phenomenon. Reduction of proportions of females in clutches in the $\mathrm{F}_{1}$, even while likely of little overall popula- 
tion consequence in a given year, could be of significance locally through reduction of local population density on the breeding grounds. This then allows the possibility of population expansion by either black ducks or mallards through pioneering into unoccupied habitat. For example, over time, where wild mallards are in greater relative numbers, in areas where mallards have been propagated and released, or where large feral flocks of mallards occur, the consequence would be a diminution of the proportion of black ducks. This phenomenon adds additional difficulty in attempts to distinguish between the consequences of hybridization and other phenomena, such as competitive exclusion or simple loss of reproductive effort through formation of hybrid pairs.

Longcore et al. (2000) concluded that current rates of hybridization of black ducks with the mallard were not "critical," because assortive mating still occurs throughout black duck range even though island populations or others in circumscribed habitats were at risk. Ankney et al. (1989) drew essentially opposite conclusions from quite similar data sets. The data we present show that several phenomena may be of consequence locally and that distinguishing the factors contributing to range shifts between the species may be more difficult than suspected. Our analysis is the first to document a postmating mechanism that isolates black ducks and mallards.

\section{Acknowledgments}

We thank parties acknowledged in Kirby et al. (2000) and Shutler et al. (1996) again for their assistance. F.B. Lee provided personal communication regarding the mating trials of birds in North Dakota. D.J. Hoysak shared the data set on hybrid ducklings in Canada. C.D. Ankney, P. Castelli, M.J. Conroy, J.R. Longcore, J.D. Nichols, and J.R. Serie are thanked for their review of early drafts of the paper.

\section{References}

Anderson, M.G., Rhymer, J.M., and Rohwer, F.C. 1992. Philopatry, dispersal, and the genetic structure of waterfowl populations. In Ecology and management of breeding waterfowl. Edited by B.D.J. Batt, A.D. Afton, M.G. Anderson, C.D. Ankney, D.H. Johnson, J.A. Kadlec, and G.L. Krapu. University of Minnesota Press, Minneapolis. pp. 365-395.

Ankney, C.D., Dennis, D.G., Wishard, L.N., and Seeb, J.E. 1986. Low genic variation between black ducks and mallards. Auk, 103: 701-709.

Ankney, C.D., Dennis, D.G., and Bailey, R.C. 1987. Increasing mallards, decreasing American black ducks: coincidence or cause and effect? J. Wildl. Manag. 51: 523-529.

Ankney, C.D, Dennis, D.G., and Bailey, R.C. 1989. Increasing mallards, decreasing American black ducks - no evidence for cause and effect: a reply. J. Wildl. Manag. 53: 1072-1075.

Arnold, T.W., Howerter, D.W., Devries, J.H., Joynt, B.L., Emery, R.B., and Anderson, M.G. 2002. Continuous laying and clutch-size limitation in mallards. Auk, 119: 261-266.

Avise, J.C., Ankney, C.D., and Nelson, W.C. 1990. Mitochondrial gene trees and the evolutionary relationship of mallards and black ducks. Evolution, 44: 1109-1119.

Barske, P. (Editor). 1968. The black duck, evaluation, management, and research: a symposium. Atlantic Flyway Council and Wildlife Management Institute, Washington, D.C.
Blums, P., and Mednis, A. 1996. Secondary sex ratio in Anatinae. Auk, 113: 505-511.

Clutton-Brock, T.H. 1986. Sex ratio variation in birds. Ibis, 128: 317-329.

Cochran, W.G. 1977. Sampling techniques. 3rd ed. John Wiley and Sons, New York.

Conroy, M.G., and Krementz, D.G. 1990. A review of the evidence for the effects of hunting on American black ducks. Trans. N. Am. Wildl. Nat. Resour. Conf. 55: 501-517.

Conroy, M.J., Barnes, G.G., Bethke, R.W., and Nudds, T.D. 1989. Increasing mallards, decreasing American black ducks - no evidence for cause and effect: a comment. J. Wildl. Manag. 53: 1065-1071.

Coyne, J.A., and Orr, H.A. 1989. Two rules of speciation. In Speciation and its consequences. Edited by D. Otte and J.A. Endler. Sinauer Associates Inc., Sunderland, Mass. pp. 180-207.

Coyne, J.A., and Orr, H.A. 1997. Patterns of speciation revisited. Evolution, 51: 295-303.

Grant, P.R., and Grant, B.R. 1992. Hybridization of bird species. Science (Wash., D.C.), 256: 193-197.

Gray, A.P. 1958. Bird hybrids: a checklist with bibliography. Commonw. Bur. Anim. Breed. Genet. Tech. Commun. 13.

Guyer, M.F. 1909. On the sex of hybrid birds. Biol. Bull. (Woods Hole, Mass.), 16: 193-198.

Haldane, J.B.S. 1922. Sex ratio and unisexual sterility in hybrid animals. J. Genet. 12: 101-109.

Johnsgard, P.A. 1963. Behavioral isolating mechanisms in the family Anatidae. Proc. Ornithol. Congr. XIII: 531-543.

Johnson, D.H., Nichols, J.D., and Schwartz, M.D. 1992. Population dynamics of breeding waterfowl. In Ecology and management of breeding waterfowl. Edited by B.D.J. Batt, A.D. Afton, M.G. Anderson, C.D. Ankney, D.H. Johnson, J.A. Kadlec, and G.L. Krapu. University of Minnesota Press, Minneapolis. pp. 446-485.

Kirby, R.E., Reed, A., Dupuis, P., Obrecht, H.H., III, and Quist, W.J. 2000. Description and identification of American black duck, mallard, and hybrid wing plumage. U.S. Geol. Surv. Biol. Resour. Div. Biol. Sci. Rep. USGS/BRD/BSR-2000-0002.

Longcore, J.R., McCauley, D.G., Hepp, G.R., and Rhymer, J.M. 2000. American black duck (Anas rubripes). In The birds of North America. No. 481. Edited by A. Poole and F. Gill. The Birds of North America Inc., Philadelphia, Pa.

McCracken, K.G., Johnson, W.P., and Sheldon, F.H. 2001. Molecular population genetics, phylogeography, and conservation biology of the mottled duck (Anas fulvigula). Conserv. Genet. 2: 87-102

Nichols, J.D. 1991. Science, population ecology, and the management of the American black duck. J. Wildl. Manag. 55: 790-799.

Nudds, T.D., Miller, M.W., and Ankney, C.D. 1996. Black ducks: harvest, mallards, or habitat? Proceedings of the Seventh International Waterfowl Symposium, Memphis, Tennessee, 4-6 February, 1996. Edited by J.T. Ratti. Ducks Unlimited Inc., Memphis, Tenn. pp. 50-60.

Orr, H.A. 1997. Haldane's rule. Annu. Rev. Ecol. Syst. 28: 195-218.

Palmer, A.R. 2000. Quasireplication and the contract of error: lessons from sex ratios, heritabilities and fluctuating asymmetry. Annu. Rev. Ecol. Syst. 31: 441-480.

Palmer, R.S. (Editor). 1976. Handbook of North American birds. Vol. 2. Waterfowl (Part 1). Yale University Press, New Haven, Conn.

Parker, L.E., Bolen, E.G., and Baker, R.J. 1981. Genetic variation 
in a winter population of mallard ducks. Southwest. Nat. 26: 425-428.

Phillips, J.C. 1914. A further study of size inheritance in ducks with observations on the sex ratio of hybrid birds. J. Exp. Zool. 16: $131-145$.

Phillips, J.C. 1915. Experimental studies of hybridization among ducks and pheasants. J. Exp. Zool. 18: 69-112 + 9 plates.

Phillips, J.C. 1921. A further report on species crosses in birds. Genetics, 6: 366-383.

Price, T.D., and Bouvier, M.M. 2002. The evolution of $F_{1}$ postzygotic incompatibilities in birds. Evolution, 56: 2083-2089.
Rhodes, O.E., Jr., Smith, L.M., and Chesser, R.K. 1995. Apportionment of genetic variance in migrating and wintering mallards. Can. J. Zool. 73: 1182-1185.

Rusch, D.H., Ankney, C.D., Boyd, H., Longcore, J.R., Montalbano, F., III, Ringelman, J.K., and Stotts, V.D. 1989. Population ecology and harvest of the American Black duck: a review. Wildl. Soc. Bull. 17: 379-406.

Shutler, D., Ankney, C.D., and Dennis, D.G. 1996. Could the blood parasite Leucocytozoon deter mallard range expansion? J.Wildl. Manag. 60: 569-580. 